\title{
The role of respondent characteristics in tracking on longitudinal surveys: evidence from the UK Millennium Cohort Study
}

\author{
Lisa Calderwood \\ Centre for Longitudinal Studies, Institute of Education, University of London \\ l.calderwood@ioe.ac.uk
}

(Received December 2012 Revised May 2013)

\begin{abstract}
Longitudinal surveys typically devote considerable resources to tracking procedures designed to minimise attrition through failure to locate sample members who move. Although these tracking procedures are often very successful, there is relatively little methodological evidence about the relative success, and cost-effectiveness, of different tracking procedures (Couper \& Ofstedal, 2009). This paper extends the existing literature by exploring the effectiveness of office tracking and field tracking separately, and by examining the role of respondent characteristics as a determinant of tracking success rates. These issues are explored using the Millennium Cohort Study, a large-scale birth cohort study in the UK. The existing research on tracking procedures has been based on household panel surveys, but in the context of a birth cohort study with relatively high mobility rates among the study population and longer intervals between waves, the effectiveness of office tracking procedures is particularly important. Our main finding, that respondent characteristics are related to overall tracking success rate, implies that survey practitioners should consider ways of improving their tracking procedures for certain groups of respondents who are the least likely to be located through existing methods.
\end{abstract}

Keywords: tracking; attrition; mobility; non-response; Millennium Cohort Study

\section{Introduction}

As longitudinal surveys aim to follow sample members over time, they employ a range of procedures designed to minimise sample loss due to failure to locate those who move. From a scientific perspective, this is crucially important. As residential mobility is driven by social processes such as relationship and employment changes, failure to locate mobile sample members can lead to biased estimates of change in these and other important domains of substantive interest to data users.

Many longitudinal surveys have developed highly successful procedures to minimise sample loss through failure to locate. For example, the Panel Survey of Income Dynamics (PSID) and the Health and Retirement Study (HRS) successfully located 97-98 per cent of sample members who moved between the 2003-2005 and 2002-2004 waves of these US panel studies, and the German Socio-Economic Panel (GSOEP) and the British Household Panel Survey (BHPS) have tracking rates of 96 per cent and 94 per cent respectively (Couper \& Ofstedal, 2009). These authors also show that in PSID and HRS, around 90 per cent of sample members who move and were located, took part in the next wave of data collection. Similarly, research on the Millennium Cohort Study (MCS) in the UK has shown that conditional on location, families who moved after wave 1 were as likely as nonmobile families to take part in wave 2 (Plewis, Ketende, Joshi, \& Hughes, 2008). This combination of high rates of tracking and a high likelihood that located sample members will be interviewed, 
means that the resources involved in tracking on longitudinal surveys are generally viewed as 'money well spent' by survey practitioners.

However, as Couper and Ofstedal (2009) point out, there is very little methodological evidence on the relative success, and cost-effectiveness, of different tracking procedures. They argue that survey design features, such as the interval between waves and the tracking procedures used, are a major determinant of tracking success and as these are under the control of survey practitioners, research should focus on optimising their design and evaluating their cost-effectiveness. This has led to increasing interest in improving the effectiveness of tracking procedures and in particular, on the optimal design of between-wave mailings, with randomised experiments being carried out on these mailings on the BHPS (Fumagalli, Laurie, \& Lynn, 2010), PSID (McGonagle, Couper, \& Schoeni, 2011) and the MCS (Calderwood, 2012). Although this research has undoubtedly improved knowledge in relation to between-wave mailings, there has been little attention in the literature to other tracking procedures.

This paper extends the existing literature by exploring the effectiveness of tracking carried out remotely in the office prior to the start of data collection and tracking carried out by interviewers in the field during data collection, and investigating how respondent characteristics are related to tracking success. By examining both office and field tracking, we provide indicative evidence on costeffectiveness; as office tracking is remote, it is less expensive than field tracking, and therefore increasing the proportion of movers that are located using office-based methods should lead to an improvement in cost-effectiveness. For longitudinal surveys with high mobility rates, long intervals between waves and without the resources to carry out field tracking, improving the effectiveness of office tracking will be particularly important. This paper also addresses the role of respondent characteristics as a determinant of tracking success rates. We examine how the office tracking rate, field tracking rate and overall tracking rate are related to a range of respondent characteristics which we hypothesise may be related to tracking success. If certain types of sample members are more difficult to locate than others, or more likely to be located through different tracking methods, this may have implications for survey practice and the design of tracking procedures. For example, it may be that tracking procedures should be tailored for different types of respondents. To our knowledge the relationship between the characteristics of sample members and tracking success has not been explored directly before.

We examine these different tracking success rates using data from the Millennium Cohort Study, a large-scale birth cohort study in the UK. We explore mobility over a two-year period between wave 2 (at age 3 ) and wave 3 (at age 5), for families who took part at wave 2. As this is a study of families with young children, the between-wave mobility rate is relatively high. Around one in five (21\%) of the wave 2 co-operating families had moved in this two-year period. The interval between waves on cohort studies is not fixed, rather it varies with the age of the sample member, so unlike panel surveys, which tend to have relatively short, fixed intervals between waves, cohort studies can have much longer intervals between waves. In this context, increasing the proportion of movers located using office tracking procedures is particularly important.

The next section reviews the existing evidence in this area and develops our hypotheses, the third section describes the data and methods that we use, the fourth and fifth sections present and discuss our results and the final section concludes with some implications for survey practice and recommendations for further research.

\section{Background}

The extensive range of tracking procedures that can be employed by longitudinal surveys is welldocumented and there are several examples in the literature reporting the procedures used on different surveys. The earliest examples of published research on this topic are from the US in the 1960s and 1970s, published by the American Association of Public Opinion Research. Eckland (1968) presents tracking rates from several US longitudinal surveys carried out in the 1960s and reviews the tracking procedures used on these studies (which include postal and telephone services and directories, other public records, and employing local co-ordinators to search at 'grassroots' level). Crider, Willits, \& Bealer, (1971) and McAllister, Goe, \& Butler, (1973) extend this literature by reviewing the tracking procedures 
used on a particular large-scale longitudinal survey and emphasising the need to collect extensive contact information, including full names and date of birth of study participants and the details of contact persons i.e. friends and/or relatives of sample members who may know where they are if they moved.

More recently, Laurie, Smith, \& Scott, (1999) reviewed the tracking procedures used on the British Household Panel Survey. They make a distinction between prospective and retrospective tracking procedures. Prospective tracking aims to prevent loss of contact in the event of a change of address by ensuring that multiple alternative methods of contacting sample members are collected and kept as up-to-date as possible. This includes collecting email addresses and multiple phone numbers from sample members as well as the contact details of one or more contact persons. Most surveys encourage sample members to get in touch with changes to their contact information by providing toll-free telephone numbers, email addresses and websites. 'Keep-in-touch' mailings are also often sent between waves of data collection to prompt sample members to confirm or update their contact details. These mailings can also lead to the discovery of a move, if they are returned to sender by the current occupiers. Retrospective tracking involves trying to find sample members who are known to have moved. This includes attempting to contact the new occupiers and neighbours of the sample member's last known address and the contact persons given by sample members. This can be done by post, telephone, email or face-to-face. Retrospective tracking can also include seeking new addresses and other contact information in public records such as electoral roles, phone and postal directories as well as administrative data sources.

Couper and Ofstedal (2009) extend this classification of tracking methods by making a further distinction between office tracking and field tracking. Office tracking is often prospective e.g. sending out between-wave mailings and processing returns, receiving updates to contact information from sample members. It can also be retrospective, involving active attempts to locate sample members who are known to have moved through e.g. post office returns from between-wave mailings. Sometimes office-based tracking can involve automated processing of large numbers of cases at the same time e.g. matching to administrative records, which is a more efficient use of resources than case-by-case review. However, often officebased tracking, for example sending emails, letters, making phone calls and searching directories, does require staff to review cases individually. This can be resource intensive, particularly for large-scale surveys. As this is done remotely, usually from a centralised location, it is less expensive than field tracking, which involves interviewers making personal visits to the last known addresses of sample members, their neighbours and contact persons. This incurs additional direct costs of travel in addition to the labour costs associated with making these tracking attempts. Field tracking is usually only carried out on longitudinal surveys which use face-to-face data collection. It is relatively uncommon for surveys which use only remote methods of data collection to use fieldbased tracking, though this is not unheard of, particularly for local area surveys. However, face-toface surveys typically only carry out field tracking during data collection waves, rather than between waves.

The difference in the relative costs of field tracking compared with office tracking implies that face-to-face longitudinal surveys should aim to locate as many movers as possible using officebased methods prior to the start of data collection for a wave, in order that resources are only used on more expensive interviewer tracking in the field for sample members who cannot be located through office tracking. However, office tracking can only be carried out prior to data collection for known movers, and it is not usually possible to identify all movers prior to the start of fieldwork i.e. some sample members may not be identified as movers until the interviewer visits the issued address. In addition, very recent moves, which take place during the data collection period, cannot, by their nature, be identified before the start of fieldwork. For this reason, office and field tracking are often carried out iteratively during the data collection period. Movers identified by interviewers during fieldwork, but for whom a new address cannot be found through field tracking, are returned for office tracking during the data collection period, and subsequently re-issued to interviewers if a new address is found. 
Overall tracking success will depend largely on the range of tracking procedures adopted by the study and the amount of resources devoted to tracking. Many large-scale longitudinal surveys employ a wide range of tracking procedures, both prospectively and retrospectively and in the office as well as in the field, and for this reason have very high rates of tracking success. For example, the Panel Survey of Income Dynamics (PSID) and the Health and Retirement Study (HRS) successfully located 97-98 per cent of sample members who moved between the 2002-2004 and 2003-2005 waves of these US panel studies, and the German Socio-Economic Panel (GSOEP) and the British Household Panel Survey (BHPS) have tracking rates of 96 per cent and 94 per cent respectively (Couper and Ofstedal, 2009).

However, as well as being a function of the amount of tracking effort made by the study, tracking success is also related to the behaviours of the study members themselves. Tracking is sometimes characterised as something that is 'done to' sample members, but it is important to remember that they can influence how easy or difficult it is for the study to locate them if they move. An obvious example of this is by notifying the study team when they move. Other behaviours likely to be associated with tracking success include leaving a forwarding address with neighbours/new occupiers, responding to keep-in-touch exercises and providing multiple sources of contact information. It is plausible to hypothesise that different types of respondents, living in different circumstances, may be more or less likely to exhibit these behaviours, and hence that respondent characteristics may be related to tracking success. In general, very little attention has been given in the literature to how the characteristics of movers are related to the likelihood of successful tracking; to our knowledge the relationship between the characteristics of sample members and tracking success has not been explored directly before.

Couper and Ofstedal (2009) discuss the role of respondent characteristics in tracking success and argue that individuals with large family and social networks will be easier to locate then individual who are socially isolated. However, due to the high overall tracking rate in the HRS and PSID, they do not examine how individual characteristics are related to tracking success. Call (1990) explores how individual characteristics are related to the number of contact persons given by respondents on the National Survey of Families and Households in the US. They find that younger and older respondents, ethnic minorities and single persons provided fewer contact persons. Although they acknowledge that this may be because such individuals have fewer potential contacts to provide, rather than as a result of unwillingness, it is nevertheless likely that respondents who provided fewer contact persons will be less easy to locate if they move. The literature on between-wave mailings also shows that younger sample members (McGonagle et al., 2011), lower-educated sample members and those who speak languages other than English at home (Calderwood, 2012) are less likely to return these mailings, which also makes successful tracking less likely. We hypothesise that a range of individual, family and housing characteristics will be associated with tracking success.

In relation to individual characteristics, we expect age, ethnic group and education to be related to tracking success. Specifically, it is hypothesised that younger, non-white and lowereducated sample members are less likely to be successfully tracked. Previous research has established that younger sample members, those from non-white ethnic groups and lower-educated sample members tend to have lower response rates on many longitudinal surveys, and we would expect these characteristics to also be negatively associated with tracking success. For some minority groups, poor English language skills may also make tracking more difficult, particularly tracking through members of the extended family e.g. grandparents.

In relation to family characteristics, we expect family type and family employment situation to be associated with tracking success. We also hypothesise that lone parents will be less likely to be successfully tracked than couple families. In part, this is because lone parent families tend to have lower response rates in general than couple families and we expect this to also be related to tracking success. Additionally, for lone parent families, it is likely that less contact information will be available to use for tracking i.e. we only have contact details for one respondent and one contact person, whereas in couple families, we collect contact details for two respondents and, for many families, two contact persons i.e. one for each parent. We expect that sample members in paid employment will be more likely to be tracked than those who are 
not in work. This is primarily because employment tends to be positively associated with taking part overall.

In relation to housing characteristics, we hypothesise that tenure and accommodation type will be associated with tracking success. Specifically, we expect that sample members living in rented accommodation and those living in flats will be less likely to be successfully tracked than families living in owner-occupied accommodation and in houses. Living in rented accommodation is associated with less stability in terms of residential moves, which in turn is likely to be associated with lower rates of tracking success, as renters are, in general, less likely to develop social ties with their neighbours and less likely to leave forwarding addresses for new occupiers. New tenants of rented properties may also be less likely to return mailings for previous occupants to their sender, meaning that moves may remain undiscovered for longer. This is also true of the new occupants of flats, rather than houses, particularly flats which are part of multipleoccupancy blocks. Flats can also be more difficult for interviewers to gain access to than houses, which makes it more difficult to speak to new occupants and neighbours, and is another reason to expect that tracking is less successful for sample members living in flats.

We will examine how these characteristics are associated with office tracking success, field tracking success and overall tracking success. We hypothesise that the same individual, family and housing characteristics that are associated with successful tracking overall will be associated with successful office and field tracking, and that the direction of the relationships between these characteristics will be the same for both office and field tracking. Moreover, we would expect that individual characteristics will be more strongly associated with office tracking success than field and overall tracking success, because office tracking is more dependent on the proactive behaviour of respondents than field tracking.

\section{Data and Methods}

The Millennium Cohort Study (MCS) is a longitudinal birth cohort study following the lives of over 19,000 children in the UK who were born in 2000 and 2001. The sample was drawn from records of recipients of a universal benefit for children, and was initially geographically clustered by electoral ward with an over-representation of areas with high proportions of Black or Asian families, disadvantaged areas and areas in the three smaller UK countries. There have been five waves of the study so far, when the cohort member was aged 9 months, then at 3, 5, 7 and 11 years of age. At all waves, interviews were conducted with both resident parents, and from the second wave onwards, data has been collected directly from the cohort member. The study has also collected data from siblings and teachers as well as consents to link to administrative data for cohort member, parents and siblings. More information about the design of the study can be found in Plewis (2007).

The MCS employs both office and field tracking. The study provides a Freephone number, email address and a website through which cohort families can inform the study's cohort maintenance team if they change their address or contact details. Contact details for study members are updated annually between-waves through the mailing of a reply-slip which is pre-printed with all of the families' contact details i.e. address, names, phone numbers, email address and contact person details. Undelivered mail, usually indicating that the family has moved, is returned to the study by the post office, which triggers retrospective office-based tracking by the cohort maintenance team. Multiple attempts are made to contact sample members, their nominated contact person and the current occupiers of the address previously occupied by sample members through telephone, mail, email and text messaging. Specialist tracing software which combines publicly available Post Office, electoral and phone records is also used routinely in the office for individual searches. As the fieldwork for the study is carried out face-to-face, interviewers also attempt to track families who have moved by making personal visits to the last known addresses of cohort members, neighbours and, if local, their contact persons, in addition to attempting contact through phone and mail. During the fieldwork period, movers who cannot be located by interviewers are returned for office tracking.

This paper examines tracking between wave 2 , carried out at age 3 in 2003-4 and wave 3, which took place at age 5 in 2006. We restrict the sample to the families who took part in wave 2 and use respondent characteristics measured at this survey in our analysis. As wave 2 was the first follow-up 
wave, and only families who were interviewed at baseline (wave 1), were followed up, almost all of the families in our sample had taken part in both wave 1 and wave $2^{i}$ i.e. there was little variation in terms of their participation history. In total, 15,590 families took part in wave 2, and 3,278 (21\%) of them had moved by wave 3 . For a very small number of families (1\%) which were not issued to the field at wave 3 it is not possible to know with certainty whether or not they moved. For all other cases, it is possible to know with a very high degree of certainty whether or not they moved because, even if they didn't participate in the survey, an interviewer visited their address and established whether or not they were still resident. This mobility rate is lower than the proportion of families who moved (over a slightly longer period) between wave 1 and wave 2 of MCS, which was 38 per cent (Plewis et al., 2008). It is very similar to the mobility rates observed in a two-year period in PSID, around 21-22 per cent (McGonagle et al., 2011) and comparable to rates observed in BHPS, around 10 per cent each year (Laurie et al., 1999).

We define the office tracking rate to be the percentage of all movers who were located using office tracking methods alone prior to the start of data collection, the field tracking rate as the percentage of movers not located by office tracking who were located by interviewers in the field, and the overall tracking rate as the percentage of all movers who were located by either office or field tracking. Under these definitions, office tracking necessarily takes place prior to the start of fieldwork and therefore prior to field tracking; so they are sequential processes. Importantly, the field tracking rate, defined in this way, is a conditional success rate i.e. we choose to analyse the outcome of field tracking only for those who were not found by office tracking. This means that the office and field tracking rates are not directly comparable. It should also be noted that some of the cases defined as being located using field tracking may have also been tracked in the office during fieldwork, and so may have been tracked through a combination of field and office tracking. It is unclear whether these cases could have been located using office tracking alone, and we therefore include them in the field tracking rate. Additionally, as it is not possible to identify all movers prior to the start of fieldwork, office tracking was not attempted for all movers prior to the start of fieldwork i.e. some of the 'movers not located through office tracking' did not actually receive office tracking (prior to the start of fieldwork).

Figure 1 gives the office and field tracking rates and Figure 2 gives the overall tracking rate. 
Figure 1. Office and field tracking rates between wave 2 and wave 3 of MCS

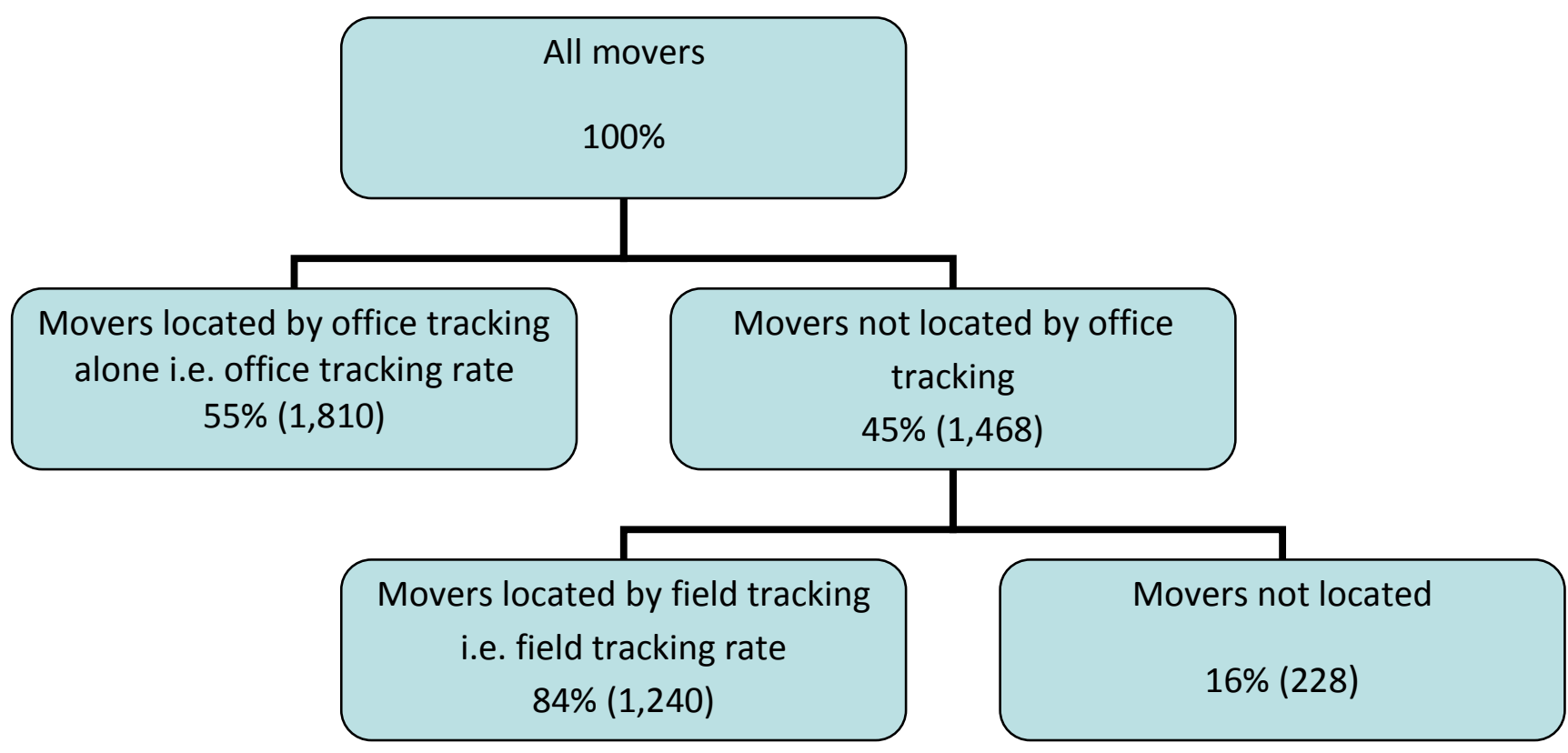

Figure 2. Overall tracking rates between wave 2 and wave 3 of MCS

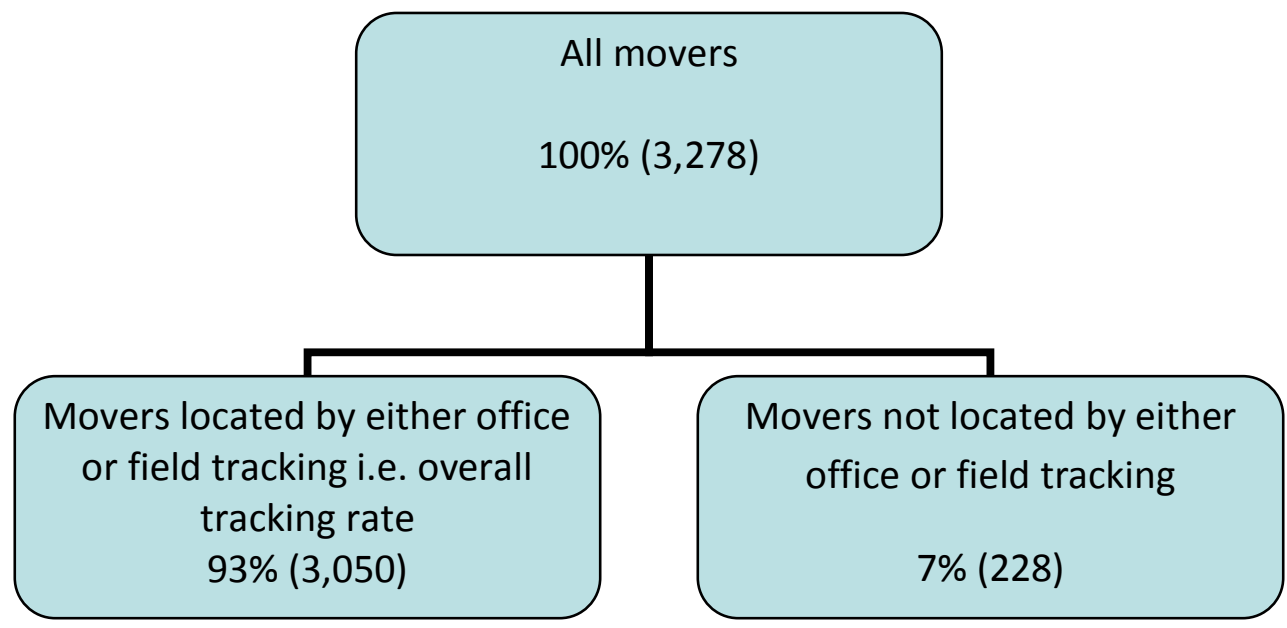

Figure 1 shows that 55 per cent of all movers were successfully located using office tracking alone prior to the start of fieldwork. This is the office tracking rate. Figure 1 also shows that, of the movers not located prior to the start of fieldwork using office tracking, 84 per cent were successfully located during fieldwork using field tracking. This is the conditional field tracking rate. Figure 2 shows that 93 per cent of all movers were located by either office tracking prior to the start of fieldwork or by field tracking. This is the overall tracking rate.
The overall level of tracking success is comparable with other major longitudinal surveys. It is encouraging that the majority of movers are located prior to the start of data collection, but it is difficult to know how this proportion compares with other surveys as there is limited published research in this area. One exception is the paper by Laurie et al. (1999) which reports that around half of movers on BHPS are found using office tracking prior to the start of fieldwork. 
Our analysis will test the hypothesis that sample members who are younger, non-white, lowereducated, lone parents, not working, living in flats or living in rented accommodation will all be less likely to be located by comparing how these characteristics, measured at wave 2 , are associated with the office, field and overall tracking rate. As noted earlier, the MCS involves interviews with up to two resident parents. The individual characteristics used, i.e. age, ethnic group and education, are those of the main respondent, who is almost always the child's natural mother. Age and ethnic group are self-reported by the main respondent. The education measure used is based on qualifications. The main respondent's highest academic or vocational qualifications are mapped to an equivalent level on a standard scale which is used in the UK for National Vocational Qualifications (NVQs). The highest level, Level 5, is equivalent to a postgraduate degree and the lowest level, Level 1 , is equivalent to a General Certificate of Secondary Education (GCSE), usually taken at age 16 , in at least one subject, awarded at the lower range of grades i.e. D-G. Family type is derived from household composition, and household employment status uses both household composition and the working status of main and partner respondents. Most partner respondents are the natural or step-father of the child. Tenure and accommodation type are reported by the main respondent on behalf of the household.

\section{Results}

Table 1 gives the office tracking rate prior to the start of fieldwork for all movers, the field tracking rate for movers not located by office tracking prior to the start of fieldwork, and the overall tracking rate for all movers, by the selected individual, family and housing characteristics of sample members at wave 2 .

Table 1 shows that ethnic group and education had a statistically significant relationship with the office tracking rate, all of the characteristics, except for age, had a statistically significant relationship with the field tracking rate, and all of the characteristics, including age, had a statistically significant relationship with the overall tracking rate. The observed relationships between the tracking rates and the characteristics chosen were in the hypothesised direction.

Looking firstly at the office tracking rate, there is a strong relationship with both ethnic group and education. For example, almost 59 per cent of white movers were located using office tracking prior to the start of fieldwork compared with around 44 per cent of Black or Black British movers. Similarly, over 60 per cent of movers with relatively high education levels (Level 4 or 5 qualifications) were located using office tracking compared with less than half, around 48/49 per cent, of those with the lowest level of education (Level 1) or no qualifications. There is also a clear age gradient in office tracking success, with older respondents more likely to be located using this method, though this relationship is not statistically significant. The office tracking rate was not related to family and housing characteristics. Although overall these results do not support our hypotheses that all of the chosen characteristics would be related to the office tracking rate, it is interesting that the only statistically significant relationships observed are with individual characteristics i.e. ethnic group and education. This supports our secondary hypothesis that individual characteristics would be most strongly related to office tracking, as this method is more dependent on the proactive behaviour of respondents than field tracking. In addition, prior research on MCS has shown that ethnic group and education are both significantly related to responding to the 'keeping-in-touch' mailing, which is one of the main office tracking methods used (Calderwood, 2012). 
Table 1. Office, field and overall tracking rates for movers by wave 2 characteristics

\begin{tabular}{|c|c|c|c|c|c|}
\hline Wave 2 characteristics & $\begin{array}{c}\text { Office } \\
\text { tracking rate } \\
\text { (\% of all } \\
\text { movers) }\end{array}$ & $\begin{array}{l}\text { Field tracking } \\
\text { rate } \\
\text { (\% of movers not } \\
\text { located by office) }\end{array}$ & $\begin{array}{l}\text { Overall } \\
\text { tracking rate } \\
\text { (\% of all } \\
\text { movers) }\end{array}$ & $\begin{array}{l}\text { Sample size } \\
\text { (all movers) }\end{array}$ & $\begin{array}{c}\text { Sample size } \\
\text { (movers not } \\
\text { located by } \\
\text { office) }\end{array}$ \\
\hline \multicolumn{6}{|l|}{$\begin{array}{l}\text { Individual characteristics (main } \\
\text { respondent) }\end{array}$} \\
\hline \multicolumn{6}{|l|}{ Age } \\
\hline $16-24$ & 51.4 & 81.8 & 91.2 & 698 & 351 \\
\hline $25-29$ & 55.2 & 84.0 & 92.8 & 768 & 358 \\
\hline $30-34$ & 58.4 & 90.4 & 96.0 & 967 & 416 \\
\hline $35-39$ & 61.0 & 88.8 & 95.6 & 602 & 237 \\
\hline $40+$ & 59.6 & 89.9 & 95.9 & 207 & 89 \\
\hline F-statistic & 2.19 & 2.33 & 3.63 & & \\
\hline$p$-value & $>0.05$ & $>0.05$ & $<0.01$ & & \\
\hline \multicolumn{6}{|l|}{ Ethnic group } \\
\hline White & 58.7 & 90.2 & 96.1 & 2652 & 1153 \\
\hline Mixed & 48.1 & 76.0 & 87.5 & 40 & 23 \\
\hline Indian & 51.4 & 75.2 & 87.9 & 63 & 30 \\
\hline Pakistani and Bangladeshi & 54.9 & 72.7 & 87.7 & 180 & 84 \\
\hline Black or Black British & 43.9 & 67.4 & 81.7 & 98 & 48 \\
\hline Other & 30.4 & 61.5 & 73.2 & 55 & 33 \\
\hline F-statistic & 4.07 & 8.67 & 15.35 & & \\
\hline$p$-value & $<0.01$ & $<0.001$ & $<0.001$ & & \\
\hline \multicolumn{6}{|l|}{ Educational qualifications } \\
\hline No qualifications & 48.3 & 77.3 & 88.3 & 498 & 246 \\
\hline Overseas qualifications only & 46.1 & 79.3 & 89.0 & 109 & 55 \\
\hline Level 1 (lowest) & 49.8 & 80.0 & 89.9 & 288 & 150 \\
\hline Level 2 & 58.1 & 90.4 & 96.0 & 936 & 414 \\
\hline Level 3 & 57.9 & 85.2 & 93.7 & 461 & 206 \\
\hline Level 4 & 61.3 & 92.2 & 97.0 & 848 & 345 \\
\hline Level 5 (highest) & 62.5 & 91.7 & 96.9 & 120 & 42 \\
\hline F-statistic & 3.39 & 4.84 & 8.00 & & \\
\hline$p$-value & $<0.01$ & $<0.001$ & $<0.001$ & & \\
\hline \multicolumn{6}{|l|}{ Family characteristics } \\
\hline \multicolumn{6}{|l|}{ Family Type } \\
\hline \multicolumn{6}{|l|}{ Married or cohabiting natural } \\
\hline parents & 56.9 & 90.0 & 95.7 & 2311 & 1021 \\
\hline Lone natural mother & 58.1 & 79.1 & 91.3 & 789 & 358 \\
\hline Other family type & 51.9 & 72.6 & 86.8 & 178 & 89 \\
\hline F-statistic & 0.86 & 13.72 & 14.73 & & \\
\hline$p$-value & $>0.4$ & $<0.001$ & $<0.001$ & & \\
\hline \multicolumn{6}{|l|}{ Household employment status } \\
\hline Main (and/or partner) in work & 57.2 & 89.9 & 95.7 & 2456 & 1105 \\
\hline Main (and partner) not in work & 56.2 & 75.3 & 89.2 & 780 & 345 \\
\hline F-statistic & 0.13 & 33.48 & 32.80 & & \\
\hline$p$-value & $<0.7$ & $<0.001$ & $<0.001$ & & \\
\hline \multicolumn{6}{|l|}{ Housing characteristics } \\
\hline \multicolumn{6}{|l|}{ Tenure } \\
\hline Own & 58.8 & 92.5 & 96.9 & 1562 & 680 \\
\hline Rent & 54.4 & 80.3 & 91.0 & 1462 & 681 \\
\hline Other & 59.3 & 87.6 & 94.9 & 211 & 88 \\
\hline F-statistic & 1.65 & 16.11 & 19.65 & & \\
\hline$p$-value & $>0.1$ & $<0.001$ & $<0.001$ & & \\
\hline
\end{tabular}


(Table 1 cont'd)

Accommodation type

\begin{tabular}{|c|c|c|c|c|c|c|}
\hline & House & 57.5 & 89.6 & 95.6 & 2607 & 1167 \\
\hline & Flat & 55.4 & 74.7 & 88.6 & 628 & 282 \\
\hline F-statistic & & 0.61 & 22.64 & 23.72 & & \\
\hline$p$-value & & $>0.4$ & $<0.001$ & $<0.001$ & & \\
\hline Sample size & & 3278 & 1468 & 3278 & & \\
\hline
\end{tabular}

Now turning to the field tracking rate, which, as noted earlier, is conditional on not being located using office tracking alone prior to the start of fieldwork. As hypothesised, this shows a statistically significant relationship with all of the chosen characteristics, with the exception of age. The higher value of the F-statistic for ethnic group and education, compared with the comparable Fstatistic for the office tracking rate, shows that the relationship between these characteristics is even stronger for field tracking compared with office tracking. This is particularly notable given the smaller sample size for field tracking, though, as noted earlier, the field tracking rate is conditional on not being located through office tracking. As with the office tracking rate, there is a clear age gradient in the field tracking rate, though it is not statistically significant. In relation to family characteristics, as hypothesised, couple families had higher field tracking rates than lone parent families (90 per cent compared with 79 per cent) and families with at least one parent employed had higher field tracking rates than those without parental employment (90 per cent compared with 75 per cent). Housing characteristics also showed the hypothesised relationships with the field tracking rate. Movers living in rented accommodation were more difficult to locate in the field than those living in owner-occupied accommodation (80 per cent compared with 93 per cent) and those living in flats were more difficult to locate in the field than those in houses ( 75 per cent compared with 90 per cent).

In relation to the overall tracking rate, as hypothesised, all of the chosen characteristics were statistically significantly associated with the overall tracking rate, including age, which was not significant for either the office or the field tracking rate when examined separately. Overall, these results provide strong evidence that respondent characteristics are important determinants of tracking success and provide support for our hypotheses regarding the relationship between tracking and age, ethnic group, education, family type, employment status, housing tenure and accommodation type.

In order to further investigate these relationships, we carried out multiple logistic regression analysis for each of the three tracking rates, in order to ascertain whether these relationships remain statistically significant when controlling for other characteristics i.e. the rest of our chosen characteristics. Table 2 gives the odds ratios associated with the office tracking rate, conditional field tracking rate and overall tracking rate from the logistic regression models, which included all of our chosen characteristics. 
Table 2. Odds ratios of being located through office tracking, being located through field tracking and being located through either office or field tracking from logistic regression models, by wave $\mathbf{2}$ characteristics

Office tracking
(all movers)
Odds ratios

$(95 \%$ CI)
Field tracking

(movers not located by office)

Odds ratios

$(95 \% \mathrm{Cl})$
Overall tracking

(all movers)

Odds ratios

(95\% Cl)

\section{Individual characteristics (main respondent) \\ Age

\begin{tabular}{lrc} 
& $16-24$ & 1 \\
$25-29$ & $1.24(0.96,1.61)$ \\
$30-34$ & $1.38(1.03,1.85)$ \\
$35-39$ & $1.69(1.23,2.34)$ \\
p-value & $40+$ & $1.77(1.13,2.77)$ \\
Ethnic group & White & 1 \\
& Mixed & $0.68(0.32,1.44)$ \\
\multicolumn{1}{c}{ Pakistani and Bangladeshi } & $0.99(0.67,1.47)$ \\
B-value & Indian & $0.75(0.39,1.44)$ \\
Black or Black British & $0.53(0.31,0.89)$ \\
Other & $0.29(0.15,0.56)$ \\
& & $<0.001$
\end{tabular}

No qualifications Overseas qualifications only Level 1 (lowest) Level 2 Level 3 Level 4 Level 5 (highest)

p-value

Family characteristics

Family Type

Married or cohabiting natural parents Lone natural mother Other family type

p-value

Household employment status

Main (and/or partner) in work Main (and partner) not in work p-value

Housing characteristics Tenure

p-value

\section{Accommodation type}

p-value

-2log likelihood

Sample size
Own

Rent

Other

1

$0.92(0.52,1.62)$

$0.99(0.67,1.46)$

$1.34(1.01,1.78)$

$1.32(0.95,1.83)$

$1.42(1.01,1.99)$

$1.36(0.74,2.52)$

$>0.1$

1

$1.14(0.88,1.47)$
$1.00(0.68,1.48)$
$>0.5$

1

$1.10(0.85,1.43)$ $>0.4$

1

$0.94(0.76,1.17)$

$1.12(0.71,1.75)$ $>0.6$

House Flat
1

$1.03(0.81,1.32)$

$>0.7$

$-2058.87$
1

$0.94(0.57,1.54)$

$1.12(0.59,2.13)$

$1.27(0.55,2.93)$

$1.17(0.44,3.12)$ $>0.9$

1

$0.60(0.18,2.06)$

$0.21(0.88,0.51)$

$0.23(0.09,0.57)$

$0.25(0.10,0.63)$

$0.11(0.04,0.31)$

$<0.001$

1

$1.31(0.44,3.95)$

$0.82(0.43,1.57)$

$1.51(0.81,2.81)$

$0.78(0.45,1.35)$

$1.67(0.85,3.29)$

$1.19(0.29,4.93)$ $>0.9$

1

$0.83(0.47,1.48)$
$0.39(0.18,0.86)$
$>0.05$

1

$0.46(0.30,0.70)$

$<0.001$

1

$0.69(0.41,1.16)$

$1.42(0.53,3.80)$

$>0.2$

1

$0.53(0.32,0.88)$

$<0.05$

$-489.29$

1,346
1

$1.02(0.64,1.63)$

$1.28(0.68,2.40)$

$1.79(0.86,3.72)$

$1.61(0.59,4.35)$

$>0.4$

1

$0.47(0.16,1.34)$

$0.22(0.09,0.54)$

$0.31(0.14,0.67)$

$0.23(0.12,0.45)$

$0.08(0.03,0.20)$ $<0.001$

1

$1.27(0.48,3.37)$

$0.73(0.42,1.26)$

$1.70(0.89,3.24)$

$0.89(0.54,1.47)$

$1.64(0.88,3.06)$

$1.37(0.36,5.14)$

$>0.1$

1

$1.01(0.57,1.79)$

$0.39(0.19,0.79)$ $<0.05$

1

$0.52(0.34,0.81)$ $<0.001$

1

$0.71(0.44,1,16)$

$1.45(0.59,3.58)$

$>0.1$

1

$0.59(0.36,0.94)$

$<0.05$

$-648.97$ 3,040

Notes. Design-based F tests (degrees of freedom omitted) were used to test the null hypothesis of no relationship between each of the characteristics and the tracking rates. The analysis was carried out using the svy commands in STATA to adjust for the sample design. Note that the -2log likelihood values are not available using the svy commands and were obtained by re-running the models without the svy commands. 
In relation to office tracking, Table 2 shows that, controlling for other characteristics, age and ethnic group are significantly related to the office tracking rate. Compared with the results from Table 1, this shows that, controlling for other factors, education is not significantly related to office tracking, whereas age is now shown to have a significant relationship with office tracking. The direction of the relationship with age and ethnic group is as expected and as we previously observed in Table 1 i.e. older respondents and white movers are more likely to be located than younger respondents and non-white movers. None of the other characteristics are significantly associated with respondent tracking.

In relation to conditional field tracking, Table 2 shows that, after controlling for other characteristics, many fewer characteristics are significantly related to the field tracking rate. In Table 1, all of the chosen characteristics except age were significantly related to field tracking, whereas, controlling for other characteristics, only ethnic group, employment status and accommodation type remain significant. The direction of the relationship between these characteristics and field tracking is as expected and as observed in Table 1 i.e. non-white, non-employed and flat-dwellers are less likely to be tracked in the field. Education, family type and tenure are no longer significantly related to the field tracking rate, controlling for other characteristics. The relationship between age and field tracking remains non-significant, controlling for other characteristics.

Similarly for overall tracking, Table 2 shows that, after controlling for other characteristics, many fewer characteristics are significantly related to the overall tracking rate. Ethnic group, family type, employment status and accommodation type are the only characteristics which remain significantly related to the overall tracking rate, controlling for other characteristics. The direction of the relationship is as expected and as observed in Table 1 i.e. non-white, other family types, non-employed, flat-dwellers are less likely to be tracked overall. Age, education and tenure are no longer significantly related to overall tracking, controlling for other characteristics.

Overall, the results from the multiple logistic regressions provide further evidence that respondent characteristics are important determinants of tracking success and show that, controlling for other characteristics, ethnic group, family type, employment status and accommodation type are strongly related to overall tracking success. However, it should be noted that the $-2 \log$ likelihood values of the models show that their overall goodness of fit is relatively low, indicating that other factors are also important.

\section{Discussion}

Overall, these results show that several respondent characteristics show statistically significant relationships with office tracking success, field tracking success and overall tracking success between wave 2 and wave 3 of the UK Millennium Cohort Study.

Controlling for other characteristics using multiple logistic regression showed that ethnic group was related to office tracking, conditional field tracking and overall tracking, age was related to office tracking but not field tracking or overall tracking, employment status and accommodation type were related to both field tracking and overall tracking but not office tracking, and family type was related to overall tracking but not office or field tracking.

Reflecting on our hypotheses in the light of these findings, it is perhaps unsurprising that ethnic group was strongly associated with tracking success, though for surveys like MCS which incorporate over-sampling of minority ethnic groups, this is particularly worrying. Further research is needed to establish the mechanisms through which ethnic group impacts negatively on tracking success, but it seems likely that our hypothesised mechanisms i.e. language barriers, affecting both office and field tracking, are part of the explanation.

It was interesting that age was the only other characteristic which was significantly related to office tracking success, and that it was not related to field or overall tracking success. This gives some support to our hypothesis that individual characteristics would be more strongly related to office tracking than field and overall tracking, as office tracking is more reliant on proactive behaviours by sample members e.g. responding to keeping in touch mailings.

Family type showed an unusual relationship with tracking success; it was not significantly related to either office or field tracking but it was related to overall tracking success, controlling for other 
characteristics. We hypothesised that the mechanism between tracking success and family type was the additional contact information provided by partners in couple families. However, there was no difference between tracking success rates for lone mother families and couple families once other characteristics were controlled for. Rather, the reason why family type was significantly related to overall tracking was due to a much lower overall tracking rate among 'other family types'. It is unclear why the tracking rate should be much lower for this group and it is surprising that tracking success rates were no different for couple parents and lone mothers, as this implies that the additional contact information collected from partner respondents is of limited value in relation to tracking. However, further research is needed before concluding this. For example, it may be that the quantity and quality of information collected from partners at wave 2 was limited.

It was surprising that employment status was significantly associated with both field and overall tracking success, controlling for other characteristics, as we did not have a clear hypothesis about the mechanism through which this was likely to have an impact on tracking success. This may be reflection of a lower level of commitment to the study among workless families. However, further research is needed to better understand the process through which employment status is related to tracking success.

It was unsurprising that housing characteristics i.e. accommodation type and tenure, both showed the strong relationships with both field and overall tracking success in the bivariate analysis, as the hypothesised mechanisms through which these characteristics were expected to influence tracking were clear and direct. However, only accommodation type, and not tenure, remained significantly associated with field and overall tracking once other characteristics were controlled for. This implies that compositional differences between owners and renters explains the relationship between tenure and field and overall tracking observed in the bivariate analysis. Conversely, the fact that accommodation type remained significantly associated with both field and overall tracking, controlling for other characteristics, shows that this relationship cannot be explained by compositional differences between the types of people living in flats and those living in houses.

\section{Conclusions}

Overall, this paper has clearly shown that respondent characteristics are related to the successful office, field and overall tracking. In doing so, this paper makes a significant contribution to the survey research literature in this area. Although there are examples in the literature which show how individual characteristics are associated with returns to between-wave mailings and collection of contact information, to our knowledge, the relationship between the characteristics of sample members and tracking success has not been explored directly before. As noted earlier, sample members are sometimes viewed as passive in discussions of tracking procedures, though it is clear that by their actions e.g. notifying the study of a change of address or inaction e.g. failure to leave a forwarding address when they move, they can influence how likely it is that they can be located when they move. Further research is needed to examine this issue in more detail, and in particular, to directly test the hypothesised mechanisms through which these characteristics are related to tracking success. However, in terms of implications for survey practice arising from this paper, given the difficulty associated with tracking families living in flats and families from non-white ethnic groups, it is clear that longitudinal surveys should consider implementing additional and/or tailored tracking methods for these groups, including the collection of additional contact information for those living in flats and use of translated tracking materials and office tracking staff/interviewers who speak minority languages for non-white ethnic groups.

This paper also explored the effectiveness of both office and field tracking, and compared how individual, family and housing characteristics were associated with both office and field tracking. Our aim was to provide evidence which would help other longitudinal surveys to increase the proportion of movers which are found using office tracking methods, which are less expensive than field tracking, and thereby improve the costeffectiveness of their tracking procedures.

Overall, we found that over half of all movers were located by office tracking prior to the start of fieldwork. We thereby demonstrated that it is possible to locate a relatively high proportion of movers using office tracking, prior to the start of fieldwork. Overall, only two of the individual characteristics i.e. age and ethnic group, were 
significantly related to office tracking success, providing some support for our hypothesis that individual characteristics would be more strongly associated with office tracking than field and overall tracking, because office tracking is more dependent on the proactive behaviour of respondents. The fact that the other characteristics were not significantly related to office tracking success implies that office tracking prior to fieldwork is not differentially effective for these different types of sample members. In some ways, this is a reassuring finding as it shows that, with the exception of younger and non-white respondents, office tracking procedures are not systematically failing to locate certain types of sample members. Attempting to improve office tracking procedures to make them more effective for younger and non-white respondents e.g. by using tailored and/or translated materials during keeping-in-touch mailings, would seem to be worth exploring.

However, we have also clearly shown the importance of field tracking to achieving high overall tracking rates. In addition, our analysis demonstrated that overall tracking success was significantly related, in the bivariate analysis, to all of the respondent characteristics. This implies that improving the effectiveness of tracking, both in the office and in the field, for these 'hard-to-locate' groups should be the primary aim of further research and improvements to survey practice.

\section{Acknowledgements}

The UK Millennium Cohort Study (MCS) is funded by the Economic and Social Research Council (ESRC) and a consortium of UK government departments, and run by the Centre for Longitudinal Studies (CLS). This research was carried out as part the Resource Centre funding for CLS from the ESRC (Ref: RES-579-47-001). I would like to thank Professor John Micklewright for helpful comments on drafts of this manuscript.

\section{References}

Calderwood, L. (2012). Improving between-wave mailings on longitudinal surveys: a randomised experiment on the UK Millennium Cohort Study. CLS Working Paper, 2012/4. London: Centre for Longitudinal Studies.

Call, V.R.A. (1990). Respondent Cooperation and Requests for Contacts in Longitudinal Research. National Survey of Families and Households Working Paper No.35. Madison: University of Wisconsin-Madison.

Crider, D.M., Willits, F.K., \& Bealer, R.B. (1971). Tracking Respondents in Longitudinal Surveys. Public Opinion Quarterly, 35, 613-620.

Couper, M.P., \& Ofstedal, M.B. (2009). Keeping in Contact with Mobile Sample Members. In P. Lynn (ed.) Methodology of Longitudinal Surveys (pp. 183-203). Chichester: John Wiley \& Sons.

Eckland, B.K. (1968). Retrieving Mobile Cases in Longitudinal Surveys. Public Opinion Quarterly, 32, 51-64.

Fumagalli, L., Laurie, H., \& Lynn, P. (2010). Experiments with Methods to Reduce Attrition in Longitudinal Surveys. ISER Working Paper Series, No. 2010-04.

Laurie, H., Smith, R., \& Scott, L. (1999). Strategies for reducing nonresponse in a longitudinal panel survey. Journal of Official Statistics, 15, 269-282.

McAllister, R.J., Goe, S.T., \& Butler, E.W. (1973). Tracking Respondents in Longitudinal Surveys: Some preliminary considerations. Public Opinion Quarterly, 37, 413-416.

McGonagle, K.A., Couper, M.P., \& Schoeni, R.F. (2011). Keeping Track of Panel Members: An Experimental Test of a Between-Wave Contact Strategy. Journal of Official Statistics, 27, 319-338.

Plewis, I. (ed.) (2007). The Millennium Cohort Study: Technical Report on Sampling (4 ${ }^{\text {th }}$. ed.). London: Institute of Education, University of London.

Plewis, I., Ketende, S.C., Joshi, H., \& Hughes, G. (2008). The Contribution of Residential Mobility to Sample Loss in a British Birth Cohort Study: Evidence from the first two waves of the Millennium Cohort Study. Journal of Official Statistics, 24, 364-385.

\section{Endnote}

'Families interviewed at wave 2 included a small number (692) of 'new' families, who were first recruited to the study at wave 2 and who had not been approached at wave 1 . 